\title{
Adsorption of 4-Chlorophenol from Aqueous Solution onto Iraqi Bauxite and Surfactant-modified Iraqi Bauxite: Equilibrium, Kinetic, and Thermodynamic Studies
}

\author{
MUNA A. AL-KAZRAGI ${ }^{1}$, DHAFIRT.A. AL-HEETIMI ${ }^{\text {* }}$ and TAKIALDIN A. HIMDAN1 \\ ${ }^{1}$ Department of Chemistry, College of Education for Pure Science, Ibn Al-Haitham University \\ of Baghdad, Baghdad, Iraq. \\ ${ }^{*}$ Corresponding anthor E-mail: dhafir1973@gmail.com
}

http://dx.doi.org/10.13005/ojc/330634

(Received: July 10, 2017; Accepted: August 05, 2017)

\begin{abstract}
Natural Bauxite (BXT) mineral clay was modified with a cationic surfactant (hexadecy Itrimethy lammonium bromide (BXT-HDTMA)) and characterized with different techniques: FTIR spectroscopy, X-ray powder diffraction (XRD) and scanning electron microscopy (SEM). The modified and natural bauxite (BXT) were used as adsorbents for the adsorption of 4-Chlorophenol (4-CP) from aqueous solutions. The adsorption study was carried out at different conditions and parameters: contact time, $\mathrm{pH}$ value, adsorbent dosage and ionic strength. The adsorption kinetic (described by a pseudo-first order and a pseudo-second order), equilibrium experimental data (analyzed by Langmuir, Freundlich and Temkin isotherm models) and thermodynamic parameters (change in standard free energy) $\left(\Delta G^{\circ}\right)$, standard enthalpy $\left(\Delta \mathrm{H}^{\circ}\right)$, and standard entropy $\left(\Delta S^{\circ}\right)$ ) were investigated and determined. Beside the advantages and properties of BXT-HDTMA (effective and low-cost adsorbent), the adsorption study revealed that the modification of natural bauxite (BXT) with hexadecy Itrimethy lammonium bromide has enhanced its adsorption capacity (eight to ten times greater comparison with the natural Bauxite).
\end{abstract}

Keywords: Adsorption, 4-Chlorophenol, Mineral clay, Natural Bauxite, Cationic surfactant.

\section{INTRODUCTION}

Chlorophenols are synthetic organic compounds that are used on a large scales in chemical industry including the production of pharmaceuticals, pesticides and dyes ${ }^{1,2}$. They can find their way to the environment since they were detected at high concentrations in wastewater treatment plant (WWTP) and discharged effluents close to industrial activities ${ }^{3}$. Due to the toxicity and carcinogenic properties, the long term exposure to chlorophenols at high concentration levels was found to cause liver, kidney and neurological defects, and therefore, their removal from water sources becomes environmentally warranted ${ }^{4,5}$. There are different physical and chemical technologies currently used for removal phenol and its derivative compounds from their aqueous solution like oxidation $^{6}$, adsorption ${ }^{7}$ and ion exchange ${ }^{8}$. 
Adsorption is one of the most effective treatment processes to remove chlorophenols from wastewater employing different types of adsorbents such as zeolite ${ }^{3}$, sepiolite ${ }^{9}$, bentonite ${ }^{10}$, and carbon nano tubes ${ }^{11}$. On the other hand, modified natural adsorbent were also found to be efficient in the removal of chlorophenols from its aqueous solution. For example, Al-Dujaili et al., ${ }^{12}$ used a surfactantmodified bentonite and kaolinite clays for their removal and seemed to be more effective than unmodified samples. Huang et al., ${ }^{13}$ investigated the removal of phenol from its aqueous solution using octodecyltrimethylammonium chloride (OTMAC) modified attapulgite. The results showed that modified attapulgite can be effectively employed in the treatment of phenol-contaminated water.

Bauxite is yellowish brown solid clay mineral, very hard and high porosity ${ }^{14}$. It consists of aluminum oxide and silica with small amounts of impurities like $\mathrm{Fe}_{2} \mathrm{O}_{3}, \mathrm{TiO}_{2}, \mathrm{CaO}, \mathrm{MgO}, \mathrm{Na}_{2} \mathrm{O}$ and $\mathrm{K}_{2} \mathrm{O}$. The chemical characteristic of the Bauxite was formed by ternary plots of $\left(\mathrm{Al}_{2} \mathrm{O}_{3}-\mathrm{Fe}_{2} \mathrm{O}_{3}-\mathrm{SiO}_{2}\right)^{15}$. In general, minerals clays are known to have low content of organic carbon and hydrophilic character due to the nature of the interlayer spaces of the minerals. Thus, simple ion-exchange with surfactants results the minerals clays can convert from being organophilic to organophobic and also increases the minerals clays interlayers basal spacing ${ }^{16}$.

The aluminosilicate of clay mineral like (BXT) are negatively charged. These charges are occupied by inorganic ions like $\left(\mathrm{Ca}^{+2}\right.$ and $\mathrm{Na}+$ ), which have strong hydration capability in the aqueous solutions. These mono or divalent inorganic cations can be easily replaced by positively charged organic ions (like quaternary ammonium cations) of the form $\left[\left(\mathrm{CH}_{3}\right)_{3} \mathrm{NC}_{6} \mathrm{H}_{33}\right]^{+}$ resulting in an expansion of the interparticale spacing and exposure of new sorption sites of the minerals clays ${ }^{17}$.
Therefore, in the current study, we used a cationic surfactant hexadecy Itrimethy lammonium bromide (HDTMA) for the modification of natural Bauxite surface. The isotherms, kinetics and thermodynamics of 4-Chlorophenol removal ffrom its aqueous solution onto BXT mineral clay and a novel (BXT-HDTMA) were studied. Modified mineral clay was characterized using Fourier transform infrared (FTIR) spectroscopy, X-ray diffraction (XRD), and Scanning electron microscopic (SEM).

\section{EXPERMANTAL}

\section{Adsorbate and Adsorbent}

The adsorbate, 4-Chlorophenol was obtained from (Sigma-Aldrich $\geq 99 \%$ ). The adsorbent, bauxite mineral clay was obtained from Al-Nuwaifa area at Al-Anbar governorate//raq. The chemical analysis was illustrated in Table 1 by using $X$-ray florescence spectra. The cationic surfactant Hexadecy Itrimethyl ammonium bromide (HDTMA $\geq 99 \%$ ) was purchased from Sigma-Aldrich.A stock solution $(1000 \mathrm{mg} / \mathrm{L})$ was prepared by dissolving $1 \mathrm{~g}$ of 4-Chlorophenol in $1 \mathrm{~L}$ of deionized water.

\section{Preparation of surfactant impregnated mineral clay}

The clay in powder form was washed several times with excessive amount of deionized water and then was dried at $90^{\circ} \mathrm{C}$ for six hours, left to cool at room temperature and then was kept in airtight container. The BXT-HDTMA was prepared by dissolving $3.5 \mathrm{~g}$ of HDTMA in $1 \mathrm{~L}$ of deionized water and mixed with $50 \mathrm{~g}$ of bauxite and stirred for 24 hours. The suspension was then decanted, washed several times with deionized water and then dried at $90^{\circ} \mathrm{C}$ for six hours. The BXT and BXT-HDTMA in this work were sieved $(\leq 75 \mu \mathrm{m})$.

\section{Characterization of the modified adsorbent}

The minerals analysis of BXT and BXT-HDTMA were characterized using $X$-ray diffraction (XRD) technique(Shimadzu 6000 powder diffractometer (Japan) using CuK $\alpha$ radiation, $\lambda=1.5418 \mathrm{~A}^{\circ}$ at $40 \mathrm{kV}, 30 \mathrm{~mA}$ and $2 \theta$ range from

Table. 1: The chemical analysis of Bauxite (BXT).

\begin{tabular}{llllllllll}
\hline $\mathrm{Al}_{2} \mathrm{O}_{3}$ & $\mathrm{SiO}_{2}$ & $\mathrm{Fe}_{2} \mathrm{O}_{3}$ & $\mathrm{CaO}$ & $\mathrm{MgO}$ & $\mathrm{Na}_{2} \mathrm{O}$ & $\mathrm{TiO}_{2}$ & $\mathrm{~K}_{2} \mathrm{O}$ & L.O.I & Total \% \\
\hline 50.64 & 31.03 & 2.75 & 0.04 & $<0.02$ & 0.02 & 1.80 & 0.02 & 13.50 & 99.82 \\
\hline
\end{tabular}


$5-80^{\circ}$. The Fourier transforms infrared spectroscopy (FTIR) (Shimadzu 8400, Japan) in the wavenumber range of (4000 to $400 \mathrm{~cm}^{-1}$ ) was used to identify the modification of BXT.Scanning electron microscope (SEM) type-T-Scan,Vega- 111(Czech) was used to determine the surface morphology of the samples

\section{Adsorption isotherm studies}

The adsorption experiments were carried out by adding 0.3 of BXT and $0.2 \mathrm{~g}$ of BXT-HDTMA (separately) with $10 \mathrm{~mL}$ of 4 -Chlorophenol into conical flasks of $(100 \mathrm{~mL})$ at various initial concentrations of $25,50,75,100,125,150,175$ and $200 \mathrm{mg} / \mathrm{L}$. The adsorption equilibrium, adsorbent dosage, $\mathrm{pH}$, lonic strength, kinetics, temperature effect at 25,35 and $45^{\circ} \mathrm{C}$ and thermodynamics are described below. The concentration of 4-Chlorophenol was determined by measuring the absorbance using UV-VIS spectrophotometer (T80) at $280 \mathrm{~nm}$. The mass of the adsorbed sorbed amount of 4-chlorophenol $\left(q_{e}, \mathrm{mg} / \mathrm{g}\right)$ was calculated equation (1)

$\mathbf{q}_{\mathbf{e}}=\frac{\left(\mathbf{C}_{\mathbf{o}}-\mathbf{C}_{\mathbf{e}}\right) \times \mathbf{V}}{\mathbf{W}}$

Where $\mathrm{V}$ is the volume $(\mathrm{L})$ and $\mathrm{W}$ is the adsorbent mass dosage $(\mathrm{g}) \mathrm{Co} \mathrm{mg} / \mathrm{L}$ is the initail concentration and $\mathrm{Ce} \mathrm{mg} / \mathrm{L}$ the residual concentration at equilibrium). The percentage of 4-chlorophenol removal was calculated according to the equation (2).

$\% \operatorname{Removal}(\mathrm{R} \%)=\frac{\left(\mathrm{C}_{0}-\mathrm{C}_{\mathrm{e}}\right)}{\mathrm{C}_{0}} \times 100$

\section{RESUILS AND DSCUSSION}

\section{FTIR Spectra}

The FTIR spectra for BXT and (BXT-HDTMA) are shown infigures (1a and 1b), respectively. The bands in Fig. (1a) at 3618 and $3527 \mathrm{~cm}^{-1}$ can be attributed to the vibrations for the structural hydroxyl group (OH stretching). The two bands at $738 \mathrm{~cm}^{-1}$ and $914 \mathrm{~cm}^{-1}$ are credited to $\mathrm{Si}-\mathrm{O}-\mathrm{Si}$ and $\mathrm{Al}-\mathrm{O}-\mathrm{Al}$ bands respectively, while the band at $1033 \mathrm{~cm}^{-1}$ is due to Si-O band. After modification with surfactant HDTMA Fig (1b), the bands at $\left(3618,3527,738\right.$ and $\left.1033 \mathrm{~cm}^{-1}\right)$ were shifted and changed in the intensity of all bands. bands at 2920 and $2850 \mathrm{~cm}^{-1}$ in modified BXT can be attributed to the symmetric and asymmetric stretching. vibrations of $\mathrm{CH}_{3}$ and $\mathrm{CH}_{2}$ groups of the HDTMA surfactant ${ }^{18,19}$
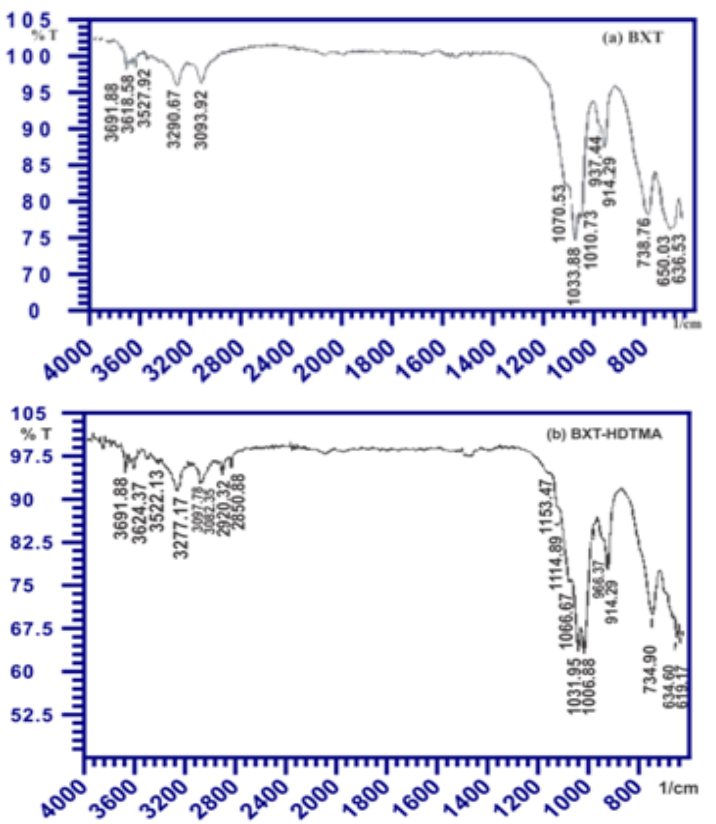

Fig.1. FTIR spectra of (a) BXT and (b) BXT-HDTMA. SEM analysis

The scanning electron microscopic demonstrates the crystalline structure, surface texture and porosity of surface materials. The SEM micrographs of BXT and BXT-HDTMA are shown in Fig.2. The micrograph in Fig.(2a) shows that the BXT has a smooth surface with flat crystal. In Fig (2b), the mineral clay lattice is shown to be swollen and fluffy. This may be related to the increase in interparticale spacing ${ }^{20}$.

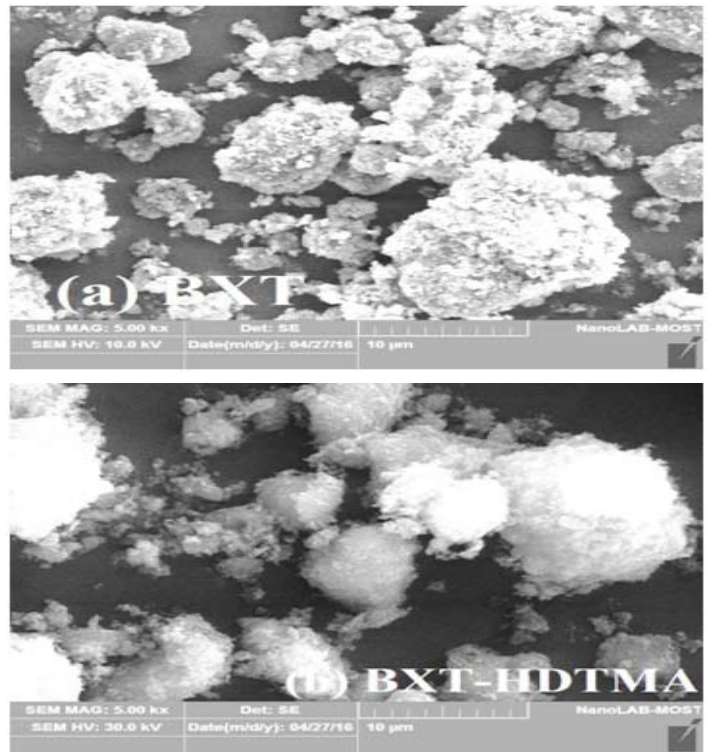

Fig.2. SEM photomicrographsfor BXT(a) and BXTHDTMA (b). 


\section{XRD analysis}

The XRD analysis of BXT and BXT-HDTMA are shown in Fig. 3a and b. The differences between BXT and BXT-HTDMA modified only the intensity of the XRD peak while there is no change in BXT mineral clay indicating that the crystalline structure remained intact and has not been destroyed after the surfactant modification, as noticed from the figure, and this is in agreement with literatures ${ }^{21,22}$.
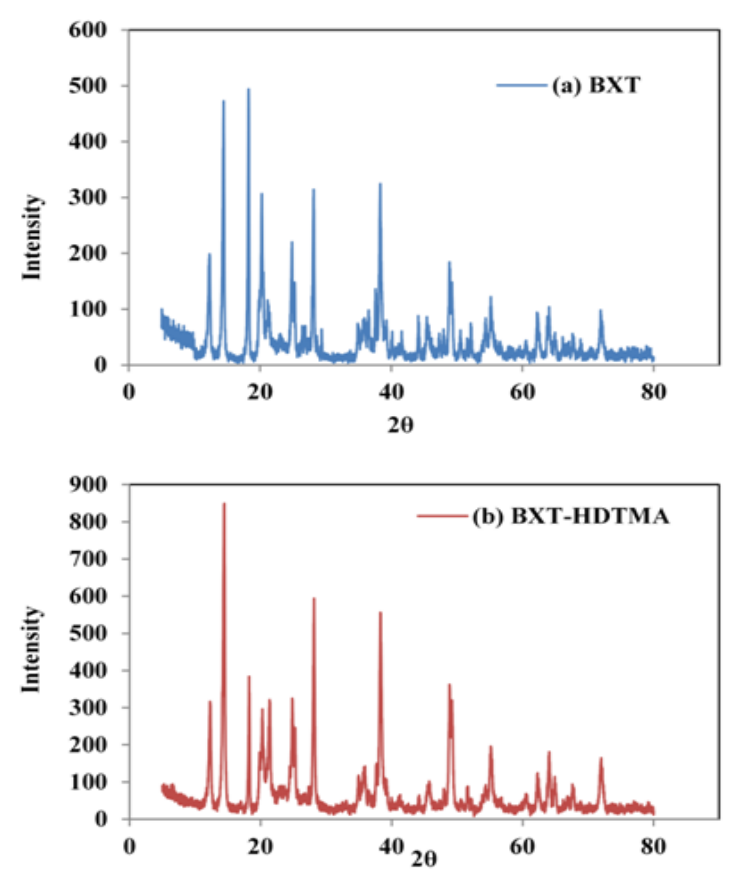

Fig.3. XRD analysis of theBXT (a) and BXT-HDTMA(b)

\section{Adsorbent dosage effect}

The effect of BXT and BXT-HDTMA dosage on the removal of 4 -Chlorophenol studied at $25^{\circ} \mathrm{C}$ and initial concentration of $100 \mathrm{mg} / \mathrm{L}$ as shown in Fig.4. The increase in the extent of removal percentage $(\mathrm{R} \%)$ of 4 -Chlorophenol on BXT after $0.3 \mathrm{~g}$ of adsorbent do not effect on the removal and the adsorption is nearly constant (65\%). On the other hand, the removal percentage of 4-chlorophenol increased with the increase in BXT-HDTMA dosage. This increase can be explained due to the abundance of free adsorbent sites and the high concentration gradient between the solution and the solid adsorbent ${ }^{23}$. In addition, the increase in removal percentage (96\%) can also be ascribed to the high surface area of the BXT-HDTMA due to the increase in interparticle space for BXT-HDTMA, which increases the removal capacity of adsorbent surface ${ }^{24}$.

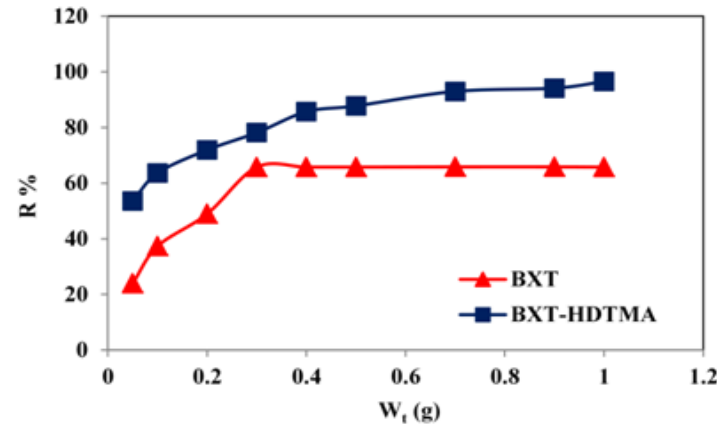

Fig.4. Effect of adsorbent dosage on the removal of 4-CP onto BXT and BXT-HDTMA at $25^{\circ} \mathrm{C}$ and $\mathrm{pH} 6.5$.

\section{Influence of contact Time}

The influence of contact time on the adsorption of 4-CP onto BXT and BXT-HDTMA was studied at an initial concentration of $175 \mathrm{mg} / \mathrm{L}$, $25^{\circ} \mathrm{C}, \mathrm{pH}=6.5$ and 0.3 and $0.2 \mathrm{~g}$ of BXT and BXTHDTMA, respectively. Adsorption capacity of 4-CP showed an increase with time and reached a constant value at a certain time. The time required to reach equilibrium was found to be 90 and $60 \mathrm{~min}$. for BXT and BXT-HDTMA, respectively, (Figure. 5).

The rapid adsorption observed at the initial stage may be related to the availability of free sites on the adsorbent surfaces. After a certain period of time, the adsorption capacity remained constant due to the less active adsorption sites being available. Notice that 4-Chlorophenol was adsorbed on BXT-HDTMA much faster BXT because the much higher affinity of the BXT-HDTMA ${ }^{25}$. The surface of BXT changed from hydrophilic to hydrophobic after modification by HDTMA. Hydrophobic surface has a greater adsorption degree than hydrophilic surface for hydrophobic chemicals s,26,27. $^{9}$.

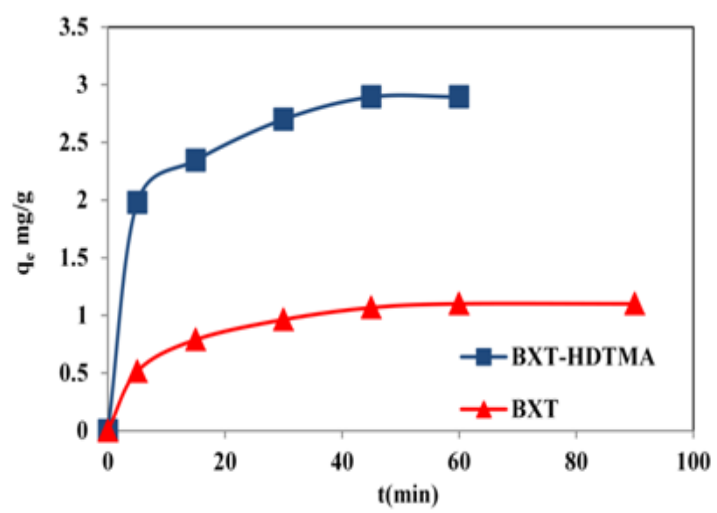

Fig. 5: Effect of contact time on adsorptionof 4-CP onto BXT and BXT-HDTMA at $25^{\circ} \mathrm{C}$ and $\mathrm{pH} 6.5$. 


\section{Influence of lonic strength}

The influence of ionic strength on the adsorption ability was studied using $\mathrm{NaCl}$ solution $(0.05,0.1$, and $0.15 \mathrm{M})$ and $4-\mathrm{CP}(100 \mathrm{mg} / \mathrm{L})$ at $\mathrm{pH}$ $=6.5$ and $25^{\circ} \mathrm{C}$. The increase in ionic strength leads to increase in adsorption capacity as shown in Fig. 6. This enhancement is due to the aggregation of 4-CP by salt in solution, which decreases the volume of the molecules and increases the hydrophobicity ${ }^{28}$. Moreover, the electrolyte in solution leads to decrease the repulsion between 4-CP and the surface by screening the columbic potential between the adsorbing molecule and charged adsorbents. The higher salt concentration leads to a positive effect on the adsorption capacity of modified clay and these explain the high ability of modified Bauxite to remove the phenolic pollutant from its aqueous solution ${ }^{29}$.

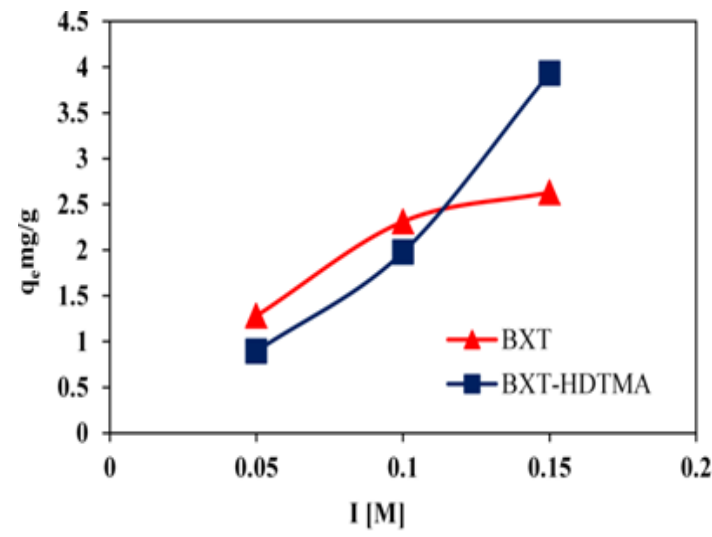

Fig.6. Effect of ionic strength on adsorption of 4CP onto BXT and BXT-HDTMA at $25^{\circ} \mathrm{C}$ and pH 6.5

\section{Influence of $\mathrm{pH}$}

The influence of $\mathrm{pH}$ on the removal of 4-CP on BXT and BXT-HDTMA was investigated at concentration of $100 \mathrm{mg} / \mathrm{L}, 25^{\circ} \mathrm{C}$ and adsorbent dosage of 0.3 and $0.2 \mathrm{~g}$ respectively. $\mathrm{NaOH}$ or $\mathrm{HCl}$ $(0.1 \mathrm{M})$ were used to obtain the desired $\mathrm{pH}$. The results are shown in Fig.7. The removal of 4-CP onto BXT and BXT-HDTMA decreased with increasing the $\mathrm{pH}$ towards basic medium. The total count of negatively charged surface was found to be greater at higher $\mathrm{pH}$ values due to the deprotonated of the surface ${ }^{17}$. This increasing in surface negative charge leads to increase the electrostatic repulsion between BXT or BXTHDTMA and 4-CP consequently decrease the adsorption. In addition, the competitive between phenoxide ions and $\mathrm{OH}$-ions to active site (positive) in surfactant can also result in a decrease in the removal percentage of $4-\mathrm{CP}^{30,23}$. At low $\mathrm{pH}, 4-\mathrm{CP}$ presents the neutral form, which shows higher adsorption affinity onto BXT and BXT-HDTMA than the anionic, because the organic phase acts as an efficient partition medium for the uptake of neutral 4-CP at acidic conditions ${ }^{31}$.

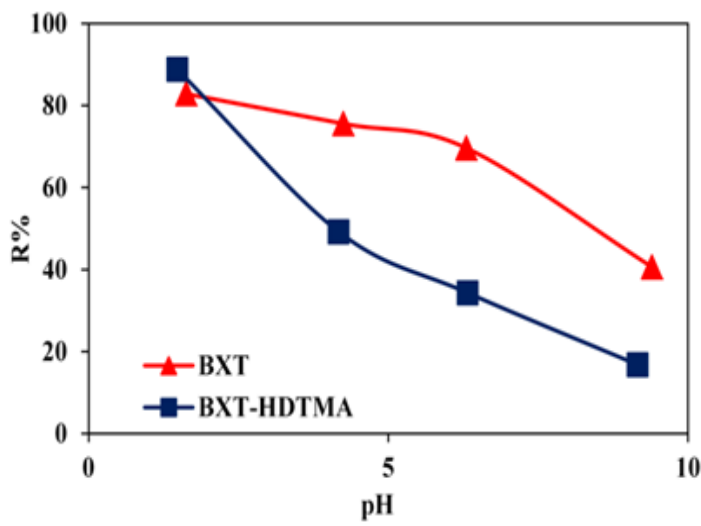

Fig.7. Effect of pH on the removal of 4-CPonto BXT and BXT-HDTMA at $25^{\circ} \mathrm{C}$.

\section{Adsorption isotherm}

The adsorption of chemical compounds can be described using one of the isotherm models that can be used to describe the adsorption type and mechanism. In the current study, three isotherm models namely: Langmuir, Freundlich and Temkin models were tested in the adsorption system ${ }^{32}$.

Langmuir isotherm was the first tested model, which assumes the formation of monolayer of adsorbate on receiving surface ${ }^{33}$. Langmuir model linear form is given in equation (3):

$\frac{\mathrm{Ce}}{\mathrm{qe}}=\frac{1}{\mathrm{~K}_{\mathrm{L}} \mathrm{q}_{\max }}+\frac{\mathrm{C}_{\mathrm{e}}}{\mathrm{q}_{\max }}$

Where $\mathrm{C}_{\mathrm{e}}$ and $\mathrm{q}_{\mathrm{e}}$ are the concentration at equilibrium ( $\mathrm{mg} / \mathrm{L})$ and the quantity of 4-chlorophenol adsorbed onto BXT and BXTHTDMA (mg/g), respectively. $q_{\max }$ is the monolayer capacity in $\mathrm{mg} / \mathrm{g}$ and $\left(\mathrm{K}_{\mathrm{L}}\right)$ is the Langmuir constant in Litre/mg. The slope $1 / \mathrm{q}_{\max }$ and intercept $1 / \mathrm{q}_{\max } \mathrm{K}_{\mathrm{L}}$ can be graphically calculated by plotting $\mathrm{C}_{\mathrm{e}} / \mathrm{q}_{\mathrm{e}}$ versus $\mathrm{C}_{\mathrm{e}}^{34}$.

The second tested model was Freundlich isotherm which normally used to describe the adsorption of heterogeneous systems ${ }^{35}$ as expressed by the following equation(4): 
$\operatorname{Logq}_{e}=\operatorname{LogK}_{F}+\frac{1}{n} \log _{e}$

(4) $\Delta \mathrm{G}^{\circ}=-\mathrm{RT} \ln \mathrm{k}^{\circ}$

Where $\mathrm{K}_{\mathrm{F}}$ (slope, mg/g) and $\mathrm{n}$ (intercept, unit less) are Freundlich constants and being calculated by plotting $\log q_{e}$ versus $\log C_{e}$. Finally, Temkin isotherm model was tested. This model assumes that the coverage of adsorbent surface would lead to the decrease of heat of adsorption. The Temkin isotherm can be calculated using equation (5):

$q e=B \ln A_{T}+B \ln C_{e}$

The plotting of $q_{e}$ versus $\ln C_{e}$ enables the calculation of the constant $A$ and $B{ }^{36}$.

From the values of the correlation coefficient $\left(R^{2}\right)$ given in Table 2 , it appears that Langmuir isotherm was found better describe the adsorption of 4-CP on BXT, While the fit of Freundlich isotherm was found to well describe the adsorption of 4-CP on BXT-HDTMA. For BXT, the maximum adsorption capacity $\left(q_{\max }\right)$ of 4-CP decreased when the temperature increased, also the adsorption energy $\left(\mathrm{K}_{\mathrm{L}}\right)$ decreased when the all temperatures increased which indicates lower affinity between the BXT surface and 4-CP where as, the maximum adsorption capacity of 4-CP onto BXT-HDTMA decreased with the increasing of temperature and that is not agreement with experimental data ${ }^{37}$.

\section{Thermodynamic parameters}

The thermodynamic parameters including Gibbs free energy $\left(\Delta \mathrm{G}^{\circ}\right)$, standard enthalpy $\left(\Delta \mathrm{H}^{\circ}\right)$, and standard entropy changes $\left(\Delta S^{\circ}\right)$ were calculated using equations (6) to (8):
Where $\mathrm{R}$ and $\mathrm{T}$ are the universal gas constant and the absolute temperature (K), respectively. The equilibrium constant $\left(\mathrm{K}_{\mathrm{o}}\right)$ was calculated as the intercept (as $\ln K_{o}$ ) of plotting $\ln K_{d}$ versus $\mathrm{C}_{\mathrm{e}}$ and extrapolating $\mathrm{C}_{\mathrm{e}}$ to 0 . The distribution coefficient $\left(K_{d} L / g\right)$ was calculated using the following equation (7):

$\mathrm{K}_{\mathrm{d}}=\frac{\mathrm{C}_{0}-\mathrm{C}_{e} \times \frac{\mathrm{v}}{\mathrm{C}_{\mathrm{e}}}}{\mathrm{w}}$

The standard enthalpy change $\left(\Delta \mathrm{H}^{\circ}\right)$ and the standard entropy change $\left(\Delta \mathrm{S}^{\circ}\right)$ were calculated using the following equation (8):

$\ln K^{\circ}=\Delta S^{\circ} R-\Delta H^{\circ} / R T$

The $\Delta \mathrm{H}^{\circ}$ and $\Delta \mathrm{S}^{\circ}$ were obtained by plotting InK $\mathrm{K}^{\circ}$ versus $1 / \mathrm{T}$ as the slope and intercept values as shown Fig. 8. Thermodynamic parameters for 4-CP adsorption on BXT and BXT-HDTMA are given in Table 3 . The standard free energy $\left(\Delta \mathrm{G}^{\circ}\right)$ was found to be negative for two systems proves that the adsorption process are spontaneous at all temperature. The negative enthalpy change $\left(\Delta \mathrm{H}^{\circ}\right)$ suggest that the adsorption of 4-CP on BXT is an exothermic process and the negative entropy change $\left(\Delta S^{\circ}\right)$ shows decrease in arbitrariness or disorder at the solid-liquid interface during the adsorption process ${ }^{38,39}$, while the positive values $\left(\Delta \mathrm{H}^{\circ}\right)$ and $\left(\Delta \mathrm{S}^{\circ}\right)$ indicate that the adsorption of 4-CP on BXT-HDTMA is endothermic process and increase in disorder and randomness ${ }^{28}$.

Table. 2: Langmuir, Freundlich and Temkin isotherm parameters for the adsorption of 4-CP onto BXT and BXT-HDTMA.

\begin{tabular}{|c|c|c|c|c|c|c|c|c|c|c|}
\hline \multirow[t]{2}{*}{ Isotherm } & \multirow[t]{2}{*}{ Adsorbent } & \multicolumn{3}{|c|}{$298 \mathrm{~K}$} & \multicolumn{3}{|c|}{$308 \mathrm{~K}$} & \multicolumn{3}{|c|}{$318 \mathrm{~K}$} \\
\hline & & $\begin{array}{c}\mathrm{K}_{\mathrm{L}} \\
(\mathrm{L} / \mathrm{mg})\end{array}$ & $\underset{(m g / g)}{q_{\max }}$ & $\mathrm{R}^{2}$ & $\begin{array}{c}\mathrm{K}_{\mathrm{L}} \\
(\mathrm{L} / \mathrm{mg})\end{array}$ & $\underset{(m g / g)}{q_{\max }}$ & $\mathrm{R}^{2}$ & $\begin{array}{c}\mathrm{K}_{\mathrm{L}} \\
(\mathrm{L} / \mathrm{mg})\end{array}$ & $\underset{(m g / g)}{q_{\max }}$ & $\mathrm{R}^{2}$ \\
\hline \multirow[t]{3}{*}{ Langmuir } & BXT & 0.013 & 1.721 & 0.995 & 0.011 & 1.696 & 0.991 & 0.009 & 1.628 & 0.969 \\
\hline & BXT-HDTMA & 0.003 & 10.869 & 0.544 & 0.004 & 9.615 & 0.829 & 0.006 & 7.692 & 0.870 \\
\hline & & $\begin{array}{c}\mathrm{K}_{\mathrm{F}} \\
(\mathrm{mg} / \mathrm{g})\end{array}$ & $1 / n$ & $\mathrm{R}^{2}$ & $\begin{array}{c}\mathrm{K}_{\mathrm{F}} \\
(\mathrm{mg} / \mathrm{g})\end{array}$ & $1 / n$ & $\mathrm{R}^{2}$ & $\begin{array}{c}\mathrm{K}_{\mathrm{F}} \\
(\mathrm{mg} / \mathrm{g})\end{array}$ & $1 / n$ & $\mathrm{R}^{2}$ \\
\hline \multirow[t]{3}{*}{ Freundlich } & BXT & 0.063 & 0.590 & 0.971 & 0.053 & 0.605 & 0.988 & 0.040 & 0.635 & 0.976 \\
\hline & (BXT-HDTMA) & 0.056 & 0.819 & 0.986 & 0.067 & 0.804 & 0.994 & 0.100 & 0.739 & 0.994 \\
\hline & & B & $A_{T}$ & $\mathrm{R}^{2}$ & $\mathrm{~B}$ & $A_{T}$ & $\mathrm{R}^{2}$ & B & $A_{T}$ & $\mathrm{R}^{2}$ \\
\hline \multirow[t]{2}{*}{ Temkin } & BXT & 0.389 & 0.124 & 0.994 & 0.371 & 0.109 & 0.983 & 0.342 & 0.098 & 0.975 \\
\hline & BXT-HDTMA & 1.224 & 0.078 & 0.879 & 1.273 & 0.086 & 0.926 & 1.269 & 0.103 & 0.921 \\
\hline
\end{tabular}




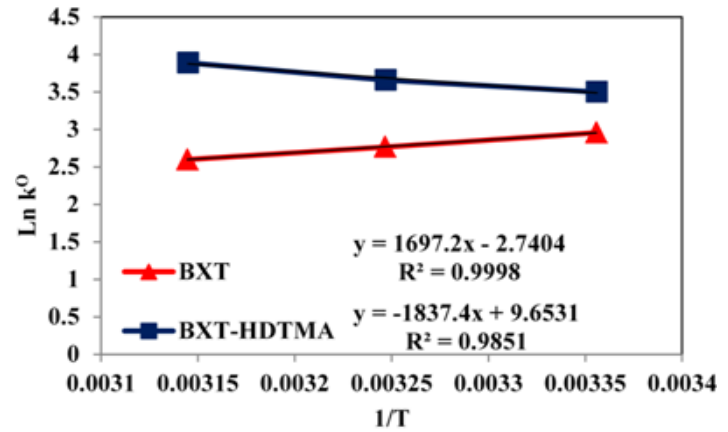

Fig.8. The relationship between $I n K^{\circ}$ and $1 / T$.

\section{Adsorption kinetic models}

The rate and kinetic of 4-CP adsorption onto BXT and BXT-HDTMA were tested using two kinetic models, namely: pseudo-first and pseudosecond order. The adsorption process was studied at 25,35 and $45^{\circ} \mathrm{C}$ on different time intervals, $\mathrm{pH}=6.5$ and an initial concentration of phenolic solution of $175 \mathrm{mg} / \mathrm{L}$. The linear form of pseudo-first order equation is represented by equation $(9)^{40}$ :

$\ln \left(q_{e}-q_{t}\right)=\ln q_{e}-k_{1} t$

Table. 3: Thermodynamic Parameters for the adsorption of 4-CP on BXT and BXT-HDTMA.

\begin{tabular}{lcccc}
\hline Adsorbent & $\mathrm{T}(\mathrm{K})$ & $\Delta \mathrm{G}^{\circ}\left(\mathrm{kJ} \cdot \mathrm{mol}^{-1}\right)$ & $\Delta \mathrm{H}^{\circ}\left(\mathrm{kJ} \cdot \mathrm{mol}^{-1}\right)$ & $\Delta \mathrm{S}^{\circ}\left(\mathrm{kJ}^{-1} \cdot \mathrm{mol}^{-1}\right)$ \\
\hline BXT & 298 & -7.32 & -14.11 & -22.78 \\
& 308 & -7.08 & & \\
BXT-HDTMA & 318 & -6.86 & & +76.79 \\
& 298 & -7.67 & +15.25 & \\
& 308 & -8.33 & & \\
\hline
\end{tabular}

Where $\mathrm{q}_{\mathrm{e}}, \mathrm{q}_{\mathrm{t}}$ and $\mathrm{k}_{1}$ are the amounts $(\mathrm{mg} / \mathrm{g})$ of 4-CPadsorbed at equilibrium, at $t$ time, and the rate constant of first order adsorption $\left(\mathrm{min}^{-1}\right)$. The value of $k_{1}$ was determined by plotting $\ln \left(q_{e}-q_{t}\right)$ versus $t$ as shown in Figure. 9.

The pseudo-second order adsorption kinetic was extrapolated using the following equation (10):

$\frac{t}{q}=\frac{1}{k_{2} q_{c}^{2}}+\frac{t}{q_{c}}$

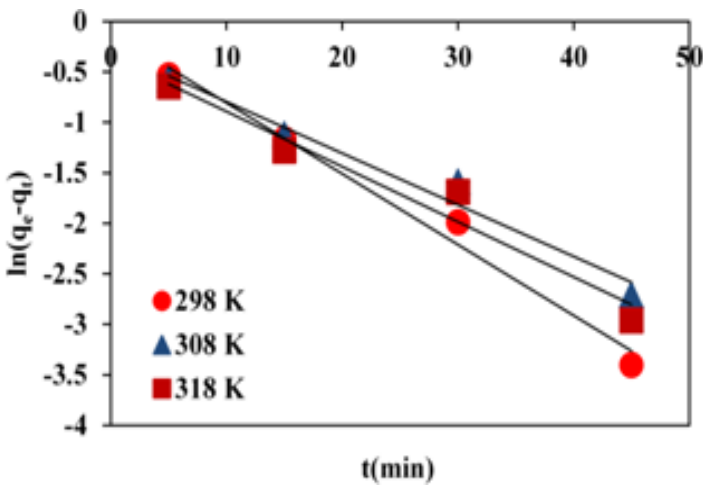

(a) BXT
Where $\mathrm{k}_{2}$ is the rate constant of pseudo second order adsorption calculated as the slope of plotting $t / q_{t}$ against time ( $t$ ) as shown in Fig 10. Table 4 illustrates the pseudo-first order and pseudosecond order kinetic parameters. The values of correlation coefficient $\left(R^{2}\right)$ indicate that the adsorption mechanism of 4-CP in the BXT and BXTHDTMA systems were fitted well to the pseudosecond order model.

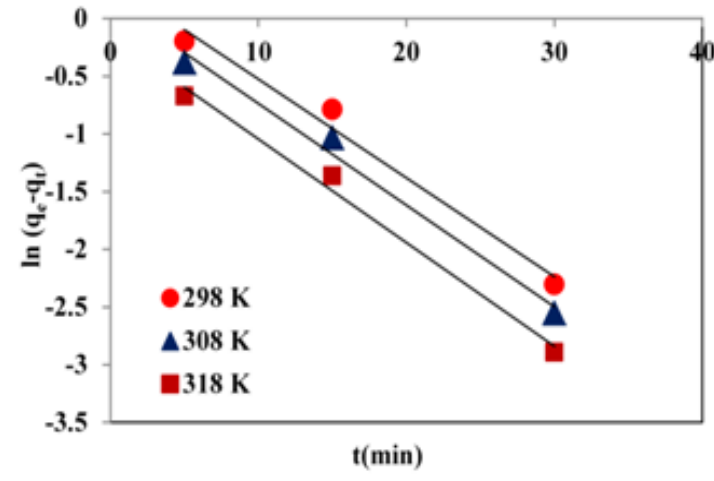

(b) BXT-HDTMA

Fig.9. Pseudo-first order plot of 4-CP adsorption onto BXT(a) and BXT-HDTMA(b). 


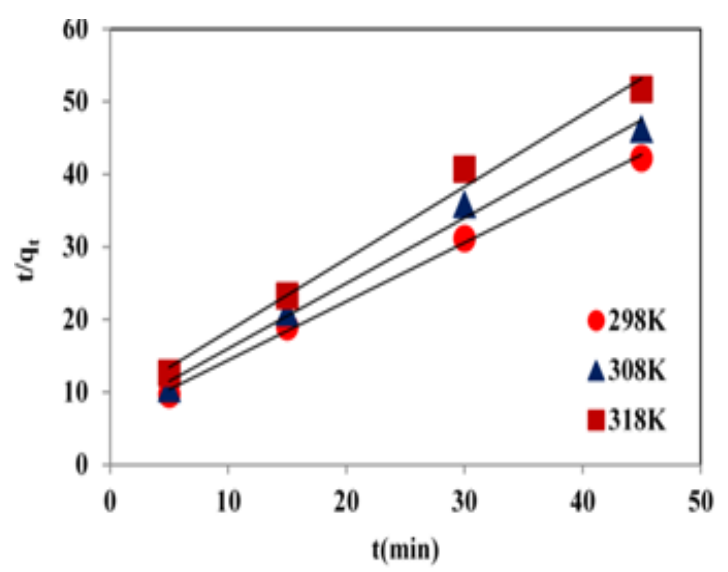

(a) BXT

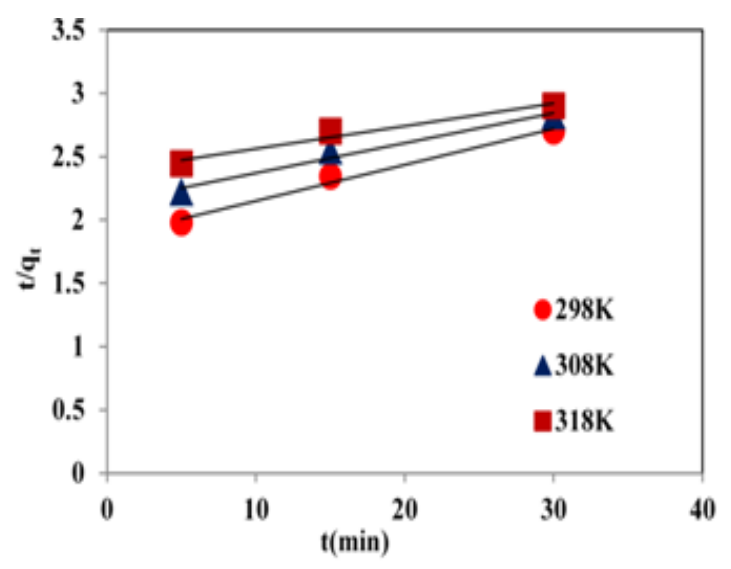

(b) BXT-HDTMA

Fig.10. Pseudo-second order plot of 4-CP adsorption onto BXT(a) and BXT-HDTMA(b).

Table. 4: Kinetic parameters for the adsorption of 4-CP onto BXT and BXT-HDTMA(C $175 \mathrm{mg} / \mathrm{L})$.

\begin{tabular}{lccccc}
\hline adsorbent & $\mathrm{T}(\mathrm{K})$ & $\begin{array}{c}\text { Pseudo-first order } \\
\mathrm{k}_{1}\left(\mathrm{~min}^{-1}\right)\end{array}$ & $\mathrm{R}^{2}$ & \multicolumn{3}{c}{ Pseudo-second order } \\
$\mathrm{k}_{2}\left(\mathrm{~g} \cdot \mathrm{mg}^{-1} \cdot \mathrm{min}^{-1}\right)$ & $\mathrm{R}^{2}$ \\
\hline BXT & 298 & 0.049 & 0.998 & 0.103 & 0.997 \\
& 308 & 0.051 & 0.971 & 0.114 & 0.991 \\
BXT-HDTMA & 318 & 0.055 & 0.956 & 0.116 & 0.990 \\
& 298 & 0.086 & 0.982 & 0.117 & 0.997 \\
& 308 & 0.088 & 0.987 & 0.158 & 0.998 \\
& 318 & 0.090 & 0.990 & 0.235 & 0.999 \\
\hline
\end{tabular}

\section{CONCLUSION}

A new adsorbent surface (BXT-HDTMA) was synthesized and tested for the removal of 4-CP from aqueous solution. The results indicated a higher adsorption of 4-CP using the modified adsorbent (BXT-HDTMA) than unmodified natural mineral clay (BXT). The adsorption isotherm of 4-CP onto BXT was fitted with Langmuir isotherm model while the adsorption isotherm of 4-CP onto BXT-HDTMA was better described using Freundlich isotherm model.
It was obtained that the adsorption mechanism represented by pseudo second-order kinetic model for both systems. The effect of temperature was investigated and used to calculate thermodynamic parameters. The analysis of these parameters explained that the adsorption of 4-CP on BXT was spontaneous and exothermic while the adsorption of 4-CP onto BXT-HDTMA was also spontaneous but endothermic.
1. Czaplicka, M. ,Sci Total Environ, 2004, 322(1), 21-39.

2. Igbinosa, E. O., Odjadjare, E. E., Chigor, V. N., Igbinosa, I. H., Emoghene, A. O., Ekhaise, F. O., and Idemudia, O. G. ,Scientific World J., 2013, 2013,1-11.

3. Apreutesei, R. E., Catrinescu, C., Ungureanu, A., and Teodosiu, C., Environ. Eng. Manag.

\section{REFERENCES}

\section{J., 2009,8(5),1053-1060}

4. Kusmierek, K., Reaction Kinetics, Mechanisms and Catalysis, 2016 , 119(1), 19-34.

5. Allaboun, H. and Abu Al-Rub, F.A., Materials, 2016,9(4):251-265.

6. Pera-Titus, M., Garcia-Molina V., Banos MA., Gimenez J. and Esplugas S., Appl. Catal. B Environ. ,2004, 47,219-256. 
7. Diaz-Nava M.C., Olguin M. T., andSolacheRios M., J. Incl. Phenom. Macrocycle Chem. 2012, 74,67-75.

8. Park, Y., Ayoko, G. A., Horváth, E., Kurdi, R., Kristof, J., and Frost, R. L., J. Colloid Interface Sci., 2013,393,319-334.

9. Yildiz, A., and Gür, A., J. Serb. Chem. Soc., 2007,72(5),467-474.

10. Yu, J.Y., Shin, M.Y., Noh, J. H., and Seo, J. J., Geosci. J., 2004,8(2):191-198.

11. Ding, H., Li, X., Wang, J., Zhang, X. and Chen, C., J.Environ. Sci., 2016, 43,187-198.

12. Al-Dujaili, A. H. ,Alkaram, U. F., and Mukhlis, A. A., J.Hazard. Mater., 2009, 169(1),324-332.

13. Huang, J., Wang, X., Jin, Q., Liu, Y. and Wang, Y. ,J. Environ. Manag. , 2007,84, 229-236.

14. Goldschmidt, V. M. ,J.Am. Chem. Soc. (Resumed), 1937,655-673..

15. Power, G., Gräfe, M., and Klauber, C ,Hydrometallurgy, 2011,108(1), 33-45.

16. Ngulube, T., Gumbo, J. R., Masindi, V., and Maity, A., J.Environ. Manag.,2017,191,35-57.

17. Park, Y. R. ,Ph.D. thesis, Queensland University of Technology, 2013.

18. Karadag, D., Turan, M., Akgul, E., Tok, S. and Faki, A., J. Chem. Eng. Data, 2007, 52(5), 1615-1620.

19. Ma, Y., Zhu, J., He, H., Yuan, P., Shen, W., and Liu, D., Spectrochim.Acta Mol. Spectros., 2010,76(2), 122-129.

20. Dutta,A., and Singh, N.,Environ. Sci. Pollut. Res., 2015, 22(5),3876-3885.

21. Hussein, M. M., Khader, K. M., and Musleh, S. M., Inter.J.Chem. Sci., 2014,12(3),815-844.

22. Mao, H., Li, B., Li, X., Yue, L., Liu, Z., and Ma, W., Ind. Eng. Chem. Res.,2009, 49(2),583-591.

23. Zhang, L., Zhang, B., Wu, T., Sun, D., and Li, Y.,Colloid Surface A., 2015, 484,118-129.

24. El-Dars, F.M., Hussien, M.Y.M., and Kandil, A. H. T.,Inter. J.Sci.Eng. Res. ,2015, 6(3),584-594.

25. Luo, P., Zhao, Y., Zhang, B., Liu, J., Yang, Y., and
Liu, J., Water Res., 2010, 44(5),1489-1497.

26. Nourmoradi, H., Avazpour, M., Ghasemian, N., Heidari, M., Moradnejadi, K., Khodarahmi, F., and Moghadam, F. M., J. Taiwan Inst.Chem. E., 2016,59,244-251.

27. Songül U., Atilla E., Mustafa U., Rafið A. and Marek M., J. Biol. Chem.,2015,43, 235-249.

28. Wang, S., Qiao, N., Yu, J., Huang, X., Hu, M., and Ma, H., Desalin. Water Treat., 2016, 57(9), 4174-4182.

29. Dong, L., Zhipeng, Z., and Yigang, D., J. Disper. Sci.Technol., 2016,37(1),73-79.

30. Kusmierek, K., and Swiatkowsk, A., J. Ecol. Chem.Eng. S., 2015, 22(1),95-105.

31. Celis, R., Koskinen, W. C., Cecchi, A. M., Bresnahan, G. A., Carrisoza, M. J., Ulibarri, M. A., and Hermosin, M. C., J.Environ.Sci. Heal.B, 1999,34(6),929-941.

32. Mahmoud, M. E., Nabil, G. M., El-Mallah, N. M., and Karar, S. B., Desalin.Water Treat., 2016,57(18),8389-8405.

33. Atkins ,P.W. , physical chemistry , $8^{\text {th }}$ ed. Oxford university press, 2006.

34. Xie, J., Meng, W., Wu, D., Zhang, Z., and Kong, H., J.Hazard. Mater., 2012,231, 57-63.

35. Maderova, Z., Baldikova, E., Pospiskova, K., Safarik, I., and Safarikova, M., Int. J. Environ. Sci. Te., 2016, 13(7), 1653-1664.

36. Kuleyin, A., J.Hazard. Mater., 2007, 144(1), 307-315.

37. Mohomed, M.A., Ibrahim, A., and Shitu, A., International Journal of Environmental Monitoring and Analysis ,2014,2,128-133.

38. Kuo, C. Y., Desalination, 2009,249(3),976-982.

39. Abdelwahab, O., and Amin, N. K. , The Egyptian Journal of Aquatic Research, 2013, 39(4), 215-223.

40. Dogan, M., Alkan, M., Demirbas, Ö.,Özdemir, Y., and Özmetin, C., Chem. Eng. J., 2006, 124(1), 89-101. 